\title{
Environmental NGOs participation in policy making: the case of the $\mathrm{PM}_{2.5}$ incident
}

\author{
Yingruo Wang ${ }^{1,2, \text { a }}$ \\ ${ }^{1}$ Faculty of Arts, University of Groningen, Oude Kijk in 't Jatstraat 26, 9712 EK Groningen,The \\ Netherlands \\ ${ }^{2}$ Globalisation Studies Groningen Institute, University of Groningen, Oude Kijk in 't Jatstraat 26, \\ 9712 EK Groningen, The Netherlands \\ ayingruo.wang@rug.nl
}

\begin{abstract}
Keywords: Civic ENGOs, environmental policy making, public participation, $\mathrm{PM}_{2.5}$
Abstract. The 20th witnessed the resurgence of China's civil society through the rapid growth of civic environmental non-governmental organizations (ENGOs). Especially since the mid-2000s, ENGOs have gradually begun to pursue policy relevant goals and play a vital role in policy formulation. The political opportunity and resource dependency theories provide a framework for explaining various factors and resources (funding, legitimacy and human) that have constrained or promoted these organizations' policy advocacy activities and the impact on their strategies utilization in this process. The purpose of this article is to examine how the institutional factors and organizational resources shape the ENGOs' policy advocacy activities and explore the role played by the ENGOs in Chinese environmental policy making process by using the case of $\mathrm{PM}_{2.5}$ campaign.

I use case studies to demonstrate how the strategies used to construct policy networks determined their success in changing policy. This finding represents an initial step in theorizing bottom-up sources of policymaking in a restrictive institutional environmental given that it create mechanism for government control over NGOs, have difficulty accessing good information for policy making from society, and a policy process formally closed to NGOs participation.
\end{abstract}

\section{Introduction}

Since the first civic ENGO Friends of Nature (FoN) founded in 1994, ENGOs have grown for years to become the key players in China's civil society. The rapidly changing social, economic, and political landscapes due to institutional reform have yielded more public resources and political opportunities to NGOs. They are actively in a variety of activities, ranging from dissemination of environmental knowledge, public environmental education, and sustainable development programs. Especially in recent years, they have played a leading role in a series of environmental activism by arousing public interests and seeking to influence policy-making, thus ENGOs have increasingly drawn attention from scholars interested in Chinese environmental politics in the last two decades [1-3]. In the process, ENGOs themselves are changing along with the dramatic transformation of the society, which is characterized as increasingly independent, internet-mobilized, alliance of peers.

As ENGOs are participating in more controversial issues which are political nature, they are also confronted with various institutional constraints. Have ENGOs grasped the opportunities and explored more spaces to engage in policy advocacy? What strategies they utilized to avoid institutional constraints? In this article, we address these questions drawing on political opportunity and resource dependency theories. Through a case study of the involvement of NGO networks in "Let me measure the air quality for my motherland" environmental campaign in 2011, this research argues that as strategic organizations, civic ENGOs play an indispensable role in environmental governance. Networks of civic ENGOs have contributed to the promotion of public participation and policy advocacy. In this campaign, ENGOs formed networks with other ENGOs and took advantage of the popularity of internet and social media to exert their influences on policy making. These strategies have allowed ENGOs to legitimize their demand for the state to open up the policy-making process for a greater degree of participation by a wider range of stakeholders. 


\section{Political opportunities and organizational resources}

Changes in political opportunities According to political opportunity theory, organizations seek to take advantage of opportunities created by political changes [4]. Social movement organizations, in particular, seek to exploit opportunities resulting from changes in institutional structures and informal power relations, of which several dimensions are especially relevant: increasing openness of the political process, unstable alignments and conflicts among political elites, and the government's decreased capacity and propensity for political repression [5].

Alongside China's reform and opening up policies, China's political system has been moving towards a more decentralized and fragmented style [6], economic and political transformation provided more social space for ENGOs to play a more active role in policy making and implementation. In addition, the central government has gradually recognized social organizations as important actors for filling gaps in improving governance. In recent years, the Chinese central government's vision for "small state, big society" has provided more opportunities and favorable environment for ENGOs growth and development. The number of NGOs started to increase rapidly during this period. Following central government's reform, governments at various levels have a more tolerated even supportive attitude toward ENGOs, which are major partners sharing burdens and responsibilities with governments, delivering public services, helping marginalized groups, and reducing social conflicts.

Organizational resources Resource dependency theory is created by Pfeffer and Salancik [7] and rooted in organizational studies. They argue that organizations have to acquire resources that they need - funding, people, information, and recognition - from the outside world to survive and grow (1978: 2).

The issue of NGO legitimacy is an important resource for environmental NGOs, especially for those in countries where civil society is an emerging phenomenon, lack of legitimacy can increase the difficulty to access to other resources such as finance, grassroots support and political networks. In China, NGOs registered through the Ministry of Civil Affairs benefit from the legitimacy and protection extended by their sponsoring agency. However, many environmental groups fail to formally register as an NGO as the registration requirements are too rigid and many groups prefer to avoid contact with the authorities. Besides of legitimacy, the resource dependency theory in organizational analysis suggests that the structure, behavior and culture of non-profit organizations would vary significantly with the type and composition of finance [8]. Studies of organizations in the third sector have used funding as the primary resource of interest as financial sources of support are critical determinants of a nonprofit agency's activity [9]. Funding shortage is always the toughest problem for Chinese civic ENGOs, even for the well-known ones. However, in recent years, civic ENGOs seek to more diversified financial resources including voluntary donations from individuals, foundations, and corporations as well as grants and contracts from governments rather than heavily depend on international foundations and government funding. In terms of human resources, at the very beginning, civic ENGOs have to struggle to keep their organizations with small and unstable staff. With the development of civic ENGOs and the growth of public environmental awareness, there are increasing full-time, part-time staff and volunteers have aspiration to join in the environmental groups. ENGOs are less constrained by staff deficiency than before.

\section{Case Review}

In November 2011, Green Beagle Environmental Institute launched a grassroots campaign "Let me measure air quality for my motherland" monitoring local air quality so that they could develop a more accurate perception of the air they were breathing. On December 18, 2011, Feng Yongfeng posted the first update in Sina Weibo to raise funds to buy a portable PM2.5 detector worth RMB 30,000 for Friends of Nature Shanghai Member Group to measure and release PM2.5 information in Shanghai. 
The distributor would later reduce the cost to 25,000 RMB, making it easier for environmental NGOs to purchase. The idea of using social media for fund raising suggests that ordinary people can make a difference for the common goods through their tiny but collective contributions. According to Feng, an individual's capacity maybe limited and the ultimate goal to have blue sky and fresh air might be far away from reach, but collective efforts can really make a difference. In one day, enough funds were raised and a detector was purchased and sent to Shanghai for air quality measurement. Feng used the same method to successfully raise financial resources from various donors for other environmental NGOs. Bike Guangzhou (拜客广州) actively responded to Feng Yongfeng's appeal, he contacted Feng Yongfeng at once and successfully reserved the permission to use the portable $\mathrm{PM}_{2.5}$ detector to measure $\mathrm{PM}_{2.5}$ in Guangzhou. Feng Yongfeng utilized his personnel resource connecting Green Hunan (绿色潇湘) with Hinaway Company (深圳赛纳威环境科技有限公司), who donated 100 portable $\mathrm{PM}_{2.5}$ detectors to grassroots NGOs. The large-scale campaign spread throughout China soon afterwards. Equipped with air quality monitoring equipment, NGOs, more than 60 volunteers and many residents set out to measure $\mathrm{PM}_{2.5}$ on their own and publicized the readings on Weibo, which attracted a flood of public attention and debate.

Finally, under public pressure, the Chinese government was determined to take action. On December 22, 2011, then Minister of the MEP Zhou Shengxian announced that a national plan with regard to $\mathrm{PM}_{2.5}$ inspection and information disclosure would be in place in 2015 . By then, the public appeal for the inclusion and disclosure of $\mathrm{PM}_{2.5}$ in the new air quality standards was addressed. In January, 2012, Beijing's government had started to release trial $\mathbf{P M}_{2.5}$ data and standards on air pollution that are more in line with World Health Organization levels. This has been "milestone" achievement for civic NGOs participation in PM2.5 governance. On February 29, 2012, the revised Ambient Air Quality Standard 《环境空气质量标准》 (GB 3095-2012) was approved by the State Council Executive Conference chaired by Premier Wen Jiabao. The revised air quality standards incorporated additional measuring indexes such as the concentration of $\mathrm{PM}_{2.5}$ and ozone $\left(\mathrm{O}_{3}\right)$ over a period of eight hours into the new air quality assessment system. $\mathrm{PM}_{2.5}$ was the very first time written into national standards and brought into compulsory supervision by provincial and municipal governments. Meanwhile, in the conference, a detailed timetable was drawn up for cities across the country to start reporting the concentration of $\mathrm{PM}_{2.5}$ and ozone $(\mathrm{O} 3)$ over a period of eight hours. The key areas and cities including Beijing-Tianjin-Hebei region, Yangtze River Delta region, Pearl River Delta region, provincial capital cities and municipalities directly under the central government were requested to carry out such enhanced supervision from 2012; 113 additional key and national environmental protection model cities from 2013; all prefecture-level cities from 2015. By 2016, the revised Ambient Air Quality Standard should be implemented nationwide.

\section{Case Analysis}

Internet and new media for arousing public interest Green Beagle Environmental Institute and other environmental NGOs have recognized and embraced to grasp the opportunities afforded by the internet and new media to organize and communicate with each other, to disseminate information, and draw support from the public. As Sullivan and Xie [10] points out, increasing visibility of environmentalism in cyberspace in which information and communication technologies play a significant role in the emergence of environmental activism. In the case of "Let me measure the air quality for my motherland", Friends of Nature, for example, with over 30,000 followers in Sina weibo, published over 210 postings regarding $\mathrm{PM}_{2.5}$. Using various publicity channels available on internet, social networking tools, and traditional media, grassroots NGOs successfully changed $\mathrm{PM}_{2.5}$, from a highly professional jargon, into an easy access word to the public at a fast speed. Without the efforts of grassroots NGOs in disseminating $\mathrm{PM}_{2.5}$ related knowledge, it was unlikely for the public to gain quick understanding of the damages caused by $\mathrm{PM}_{2.5}$ on environment and human beings. Discussions about air quality issues have become a heated topic in different social media sites. It is safe to say that 
no large-scale scientific publicity endeavor in the nation ever was as successful as the $\mathrm{PM}_{2.5}$ incident in terms of far-reaching influence, wide scope of coverage, and wide attention-drawn from the public.

ENGOs network building The "Let me measure air quality for my motherland" campaign relies on the increasing cooperation among ENGOs. Consistent with the assertions of resource dependency theory, in situations of large power asymmetries between actors, it is common for the less powerful ones to decide to work together in an attempt to challenge these power asymmetries. Green Beagle Environment Institute is aware of the challenge to influence the policy-making by its own force, therefore the founder Feng Yongfeng actively seeks cooperative partners to build networks to strengthen their power. Common policy beliefs and mobilized resources are important assets among the NGO network. Green Beagle Environment Institute, Bike Guangzhou, Green Stone Environmental Protection Center, Green Hunan, Friends of Nature Shanghai, and Friends of Nature Wuhan collaborate with each other, exchange experiences, share information and equipment resources, making this activism into a nation-wide and influential campaign at the end. The most significant effect of the NGO network is that they have a stronger collective voice getting heard and successfully changed the central government's attitude toward the $\mathrm{PM}_{2.5}$ issue. Officials have become more open and candid in their public remarks about $\mathrm{PM}_{2.5}$ and put $\mathrm{PM}_{2.5}$ monitoring and disclosure as well as emission-reducing on policy agenda.

Mobilizing allies In the "Let me measure air quality for my motherland" campaign, we can find that environmental NGOs collaborating with a third party pressurize the state. ENGOs together with Southern Weeks, an influential and wide-read newspaper in China, submitted an open letter to propose suggestions in regards of incorporation $\mathrm{PM}_{2.5}$ into air quality evaluation system. This strategy is meaningful, ENGOs inform the government about the problems they have identified, in the hope that the government can adopt their suggestions and resolve them as soon as possible; in addition, they have drawn widely attention from the public as well as the government in a mild and peaceful way. ENGOs representing the general public to express their concerns that incorporation $\mathrm{PM}_{2.5}$ into the air quality evaluation system via the open letter has successfully made their voices heard. While protest, demonstrations and other contentious methods of civil society activities are constrained and limited due to China's political environment, this case has provided a new model for the civil society to participate in China's environmental governance.

\section{Conclusion}

The $\mathrm{PM}_{2.5}$ incident finally came to an end after the new indexes, including the concentration of $\mathrm{PM}_{2.5}$, were incorporated into Ambient Air Quality Standards. This outcome not only demonstrates the positive attitude and active response of the Chinese government in dealing with environmental problems, but also shows the enhanced role played by the civil society with civic ENGOs. Civic ENGOs serving as the prominent representatives of the public in influencing public policy-making along with authorities provides a new model for civil society participation in environmental governance. ENGOs grasp the political opportunities and take advantage of all the resources which are available, such as the popularity of internet and new media, making $\mathrm{PM}_{2.5}$ incident into public debate and drawing extensive attention in a short time. Meanwhile, they build allies with social media, environmental experts, peer ENGOs and general public to boost their influence. Although the campaign did not entirely solve the air pollution problem that bothering many cities in China, governments at various levels and environmental authorities, facing public pressure inspired by the campaign, did change their attitudes toward $\mathrm{PM}_{2.5}$ issues and recognize the importance of mutual communication and collaboration with civic ENGOs in environmental governance. On the other hand, we can find that no institutional mechanisms exist to guarantee ENGOs input on government policy making and articulation of social issues. The influence of the organizations on government policy, however, remains limited and inconsistent. The fact that ENGOs participation on environmental 
governance depends so heavily on non-institutional channels reflects a pervasive weakness of Chinese ENGOs in general.

\section{Acknowledgements}

Yingruo Wang is very grateful for financial support of the China Scholarship Council (No. 201307040006). Prof. Joost Herman and Dr. Yongjun Zhao are gratefully acknowledged for the supervision of my $\mathrm{PhD}$ project.

\section{References}

[1] T. Saich, "Negotiating the state: The development of social organizations in China," China Q. Vol. 161 (2000), pp. 124-141.

[2] P. Ho, "Greening without conflict? Environmentalism, NGOs and civil society in China," Dev. Change Vol. 32 (2001), pp. 893-921.

[3] P. Ho, "Embedded activism and political change in a semiauthoritarian context," China Inf. Vol. 21 (2007), pp. 187-209.

[4] D. S. Meyer and S. Staggenborg, "Movements, countermovements, and the structure of political opportunity,” Am. J. Sociol. Vol. 101 (1996), pp. 1628-1660.

[5] D. Tartakowsky and S. Tarrow, "Power in Movement: Social Movements, Collective Action and Politics.”JSTOR, 1997.

[6] A. Mertha, “'Fragmented authoritarianism 2.0': political pluralization in the Chinese policy process," China Q. Vol. 200 (2009), pp. 995-1012.

[7] J. Pfeffer and G. R. Salancik, The external control of organizations: A resource dependence perspective. Stanford University Press, 2003.

[8] W. W. Powell and P. J. DiMaggio, The new institutionalism in organizational analysis. University of Chicago Press, 2012.

[9] B. A. Weisbrod, "Guest editor's introduction: The nonprofit mission and its financing," J. Policy Anal. Manag. Vol. 17 (1998), pp. 165-174.

[10] J. Sullivan and L. Xie, "Environmental activism, social networks and the internet," China Q. Vol. 198 (2009), pp. 422-432,. 